\title{
Characterization of Biochars Produced from Various Biowastes
}

\author{
Bayarjargal Bayartsengel ${ }^{1}$, Nomuunzaya Erdene-Ochir ${ }^{2}$, Sainzaya Battulga ${ }^{2}$, \\ Saurjan Tyeliubek ${ }^{3}$, Erdenedalai Jantsanpurev ${ }^{4}$, Buyan Chuluun ${ }^{1, *}$ \\ ${ }^{1}$ Department of Chemistry, School of Arts and Sciences, National University of Mongolia, Sukhbaatar district, \\ Ulaanbaatar 14201 Mongolia \\ ${ }^{2}$ Department of Chemical and Biological Engineering, School of Engineering and Applied Sciences, National \\ University of Mongolia, Sukhbaatar district, Ulaanbaatar 14201 Mongolia \\ ${ }^{3}$ Innovation and Business Development Center, Division of Science and Research, Mongolian University of Life \\ Sciences, Khan-Uul district, Ulaanbaatar 17024 Mongolia \\ ${ }^{4}$ Department of Agricultural Engineering, School of Engineering and Technology, Mongolian University of Life \\ Sciences, Khan-Uul district, Ulaanbaatar 17024 Mongolia \\ *Corresponding author. Email: buyan@num.edu.mn
}

\begin{abstract}
Biochar is a product of thermal degradation of organic materials in the absence of air (pyrolysis). Slowpyrolyzed and biowaste-derived biochars show excellent adsorption properties. Studies on biochars produced from pine nut shells, sawdust, and cow dung have been carried out in Mongolia determining the technical characteristics and applying for improvement of soil quality. However, a thorough characterization of biochars is still in lack. In this study, we produced 10 biochars from animal bones and dungs, and firewoods and compared their characterization properties. Physico-chemical parameters of biochars such as moisture, ash, volatile matters, fixed carbons, $\mathrm{pH}$, redox potential ( $\mathrm{pE}$ ), electrical conductivity (EC), total dissolved solids (TDS), cation exchange capacity (CEC), and base saturation were determined and SEM-EDX, FTIR, XRD, main elements, and trace metals analysis were obtained. Methylene blue and iodine absorption tests were carried out in terms of surface porosity. All biochars showed high electrical conductivity and base saturation indicating that they were rich in cations. The highest values of $\mathrm{pH}, \mathrm{EC}$, TDS, and CEC were found in biochar produced from sheep dung. Among bone chars, biochar produced from sheep spine bone showed the highest CEC. High Ca content in bone biochars resulted from the nature of the raw material. Biochars hardly contained trace metals. XRD analysis showed that the firewood biochar had amorphous, whereas the bone biochars and dungs had crystal structures. Biochars produced from animal and forestry biowastes have shown great values of adsorbent characteristics, thus the application of such biochars can simultaneously reduce waste and be an environmentally friendly valuable product.
\end{abstract}

Keywords: Biochar, Characterization, Animal bone, Firewood, Animal dung

\section{INTRODUCTION}

In recent years, the application, characteristics, and benefits of biochar produced from biomass such as agriculture, food, and forestry waste are explored vastly [1]. For instance, early Japanese farmers used to apply rice husk biochar before planting crops in fields. This biochar is called haigoe, so it was prepared by adding human waste to rice husk biochar [2]. Dutch soil scientists first studied the black soil in
Amazon Valley, named after Terra Preta de Indio, and introduced the term biochar to science [3]. Biomass is organic and non-organic solid material derived from living organisms like animal and plant wastes, food wastes, agricultural wastes, and industrial wastes. Biochar is produced by pyrolysis of biomass which is divided into woody and nonwoody. Biochar is stable carbon-rich material, it's used for renewable fuel, as well as to improve soil quality and sorbent for contaminant management in 
soil and water. Oil and synthetic gases, and biochar are products of pyrolysis that depending on temperature, pressure, and residence time [2]. Biochar consumption is divided into four main environmental sectors: soil improvement, climate change mitigation, waste management, and energy production [4]. Biochar properties are affected by several technological parameters, mainly pyrolysis temperature and feedstock kind, which differentiation can lead to a product with a wide range of values of $\mathrm{pH}$, specific surface area, pore-volume, CEC, volatile matter, ash, and carbon content [2].

Previously, the effect of temperature on the structure of biochar has been explored and the physical and chemical properties of the biochar produced were compared under different temperature conditions $[5,6,7]$. The biochar parameters most affected by the characteristics of feedstocks are the total carbon, fixed carbon, and mineral elements of biochar [1]. Usually, biochar is pyrolyzed under the slow pyrolysis method with the temperatures of $350^{\circ} \mathrm{C}, 400^{\circ} \mathrm{C}, 500^{\circ} \mathrm{C}$, and $600^{\circ} \mathrm{C}[6,7,8]$. Biochar produced from various biomass, such as coffee husk, chicken manure, and pine, were characterized and compared by physical and chemical analysis and their potential to be used as a soil amendment [9]. Biochar showed great excellence in the sorption of heavy metals $[10,11]$. Wood waste has high $\mathrm{pH}$, low CEC and high aromatic character in contrast to that chicken manure have high CEC and low aromatic character [9]. However, the characterization of various biochars produced from different biowastes is still insufficient. In the present study, biochars were produced from common livestock waste (cow and sheep bones and cow and sheep dungs) and typical firewoods (larch and pine) used in ger area in Mongolia and subsequently characterized in terms of physico-chemical, structural, and surface properties.

\section{EXPERIMENTAL}

\subsection{Biochar Production}

Three main types of animal and plant-based biowaste were selected to produce biochars, namely bones, dung, and firewoods. Cow and sheep bones were collected from the local food market and classified into thigh bones (femur), spine bones, and rib bones. Cow and sheep dung were collected from the local farms. Firewoods (larch wood and pine wood) were purchased from small sellers. All raw materials were subjected to slow pyrolysis in a toplit-up-draft (TLUD) gasifier under different temperatures and time duration depending on size and thickness [12]. The temperature was measured every 20 minutes using an infrared (IR) thermometer. The slow pyrolysis conditions were given in Table 1 . The biochars produced were air-dried at room temperature for several days. The dried biochars were crushed and ground following by sieving through standard soil sieves of the size of $0.075-0.200 \mathrm{~mm}$ and $0.200-0.300 \mathrm{~mm}$. The sieved biochars were washed with deionized water and dried at $105^{\circ} \mathrm{C}$ in an oven for one hour.

\subsection{Biochar Physico-Chemical Characterization}

Moisture content, ash content, and volatile matter were conducted according to DIN 51719 and DIN 517120 [13]. Moisture and ash content were determined at $105^{\circ} \mathrm{C}$ and $600^{\circ} \mathrm{C}$, perspectively [1]. Biochar was mixed with deionized water at the ratio of 1:5. $\mathrm{pH}$ value Redox potential ( $\mathrm{pE}$ ), electrical conductivity (EC), and total dissolved solids (TDS) of the abovementioned slurry were measured with the $\mathrm{HI}-2550 \mathrm{pH} / \mathrm{mV} /$ conductivity meter [13].

Cation exchange capacity (CEC) and base saturation of biochar were carried out with the barium acetate method $[14,15]$. Base cation $\left(\mathrm{Ca}^{2+}, \mathrm{Mg}^{2+}, \mathrm{K}^{+}\right.$, and $\mathrm{Na}^{+}$) was determined with inductively coupled plasma atomic emission spectroscopy (ICP-OES) (Agilent 5110, Agilent, Santa Clara, USA).

\subsection{Biochar Surface and Pore Characterization}

The surface morphology of ground biochars was examined using scanning electron microscopy (SEM) (TM1000 Tabletop, Hitachi, Tokyo, Japan) at the joint "Field research center" of Nagoya University and Mongolian University of Science and Technology. Microporosity and mesoporosity of biochar were estimated with methylene blue (MB) adsorption capacity and iodine adsorption number $[16,17]$. The concentration of MB was determined at $645 \mathrm{~nm}$ by the UV-Vis spectrophotometer (UV-M51, BEL Engineering, Monza, Italy). The methylene blue adsorption was calculated with the Langmuir equation [17].

\subsection{Biochar Elemental Composition}

Biochar elemental analyses of total nitrogen and total carbon were performed using a $\mathrm{CN}$ analyzer (chemical automation, Primacs SNC 100, Skalar, Breda, Netherlands) at Gatsuurt LCC laboratory. Trace metal analysis of biochar was carried out with 
Inductively Coupled Plasma Mass Spectrometry

Massachusetts, USA). instrument (ICP-MS, NexION 2000, PerkinElmer,

Table 1. Pyrolysis condition of biochars produced

\begin{tabular}{|l|l|l|l|l|l|l|l|l|l|l|}
\hline Biowaste & $\begin{array}{l}\text { Cow } \\
\text { thigh } \\
\text { bone }\end{array}$ & $\begin{array}{l}\text { Cow } \\
\text { spine } \\
\text { bone }\end{array}$ & $\begin{array}{l}\text { Cow } \\
\text { rib } \\
\text { bone }\end{array}$ & $\begin{array}{l}\text { Sheep } \\
\text { thigh } \\
\text { bone }\end{array}$ & $\begin{array}{l}\text { Sheep } \\
\text { spine } \\
\text { bone }\end{array}$ & $\begin{array}{l}\text { Sheep } \\
\text { rib } \\
\text { bone }\end{array}$ & $\begin{array}{l}\text { Cow } \\
\text { dung }\end{array}$ & $\begin{array}{l}\text { Sheep } \\
\text { dung }\end{array}$ & $\begin{array}{l}\text { Larch } \\
\text { wood }\end{array}$ & $\begin{array}{l}\text { Pine } \\
\text { wood }\end{array}$ \\
\hline Biochar & CoTB & CoSB & CoRB & ShTB & ShSB & ShRB & CoDu & ShDu & WLar & WPin \\
\hline $\begin{array}{l}\text { Pyrolysis } \\
\text { temperature, }{ }^{\circ} \mathrm{C}\end{array}$ & 550 & 550 & 500 & 550 & 500 & 500 & $400-450$ & \\
\hline Pyrolysis time, min & 90 & 70 & 70 & 90 & 60 & 60 & 45 & & \\
\hline Biochar output, \% & 73.2 & 71.8 & 69.2 & 67.6 & 63.0 & 60.7 & 52.1 & 81.4 & 41.6 & 43.2 \\
\hline
\end{tabular}

\subsection{Biochar Chemical Composition with Spectra Parameters}

The surface functional groups of biochar were identified with Fourier transform infrared spectroscopy (FTIR Spectrometer, Nicolet iS5, Thermo scientific, Massachusetts, USA). Detection of mineral phases present in the biochar was performed with X-ray diffraction (XRD) analysis (Xray diffractometer, PW 1800, Philips, Amsterdam, Netherlands).

\section{RESULTS AND DISCUSSION}

\subsection{Biochar Physico-Chemical Characteristics}

Among the various biochar types, bone biochars showed a higher percentage in the ash content from firewood and dung biochars. The minor losses in ash content after the pyrolysis process are likely due to lost potassium, which can volatilize at pyrolysis temperatures [18]. Firewood biochar is entirely organic a natural composite of cellulose fibers and high volatile content, less ash remains after burning.
The high ash content of bone biochars is due to the presence of inorganic substances and minerals in bone wastes. Bone biochar fixed carbon was less than $1 \%$, while firewood biochars were more than $50 \%$. According to [5] study, the ash content of pine biochar produced at $450{ }^{\circ} \mathrm{C}$ was $2.9 \%$, the volatile matter was $34.9 \%$, and fixed carbon was $62.2 \%$, which was consistent with our results. Ash content, volatile matter and fixed carbons of the biochars produced from different biowastes are given in Figure 1. All biochars showed high electrical conductivity and base saturation indicating that they were rich in cations. The $\mathrm{pH}$ and $\mathrm{EC}$ values of the biochars are shown in Figure 2.

The difference in $\mathrm{pH}$ value can be observed in the types of biomass: the biochar extracted from sheep dung biochar ( $\mathrm{ShDu}$ ) had the highest $\mathrm{pH}$ value (9.85) in solution, while the $\mathrm{pH}$ value of bones biochars was ranged from 8.04 to 9.11 . The results of the [19] study showed that the cow manure biochar $\mathrm{pH}$ value was 9.09, which was in agreement with the results of our study. The $\mathrm{pH}$ value and redox potential indicate that the electrons are easily transferred to the species in solution.

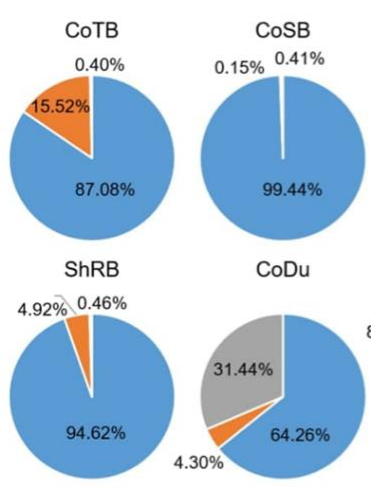

Ash contents

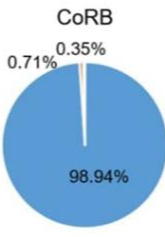

ShDu

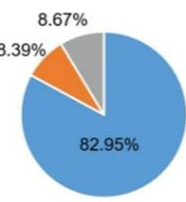

Volatile matter

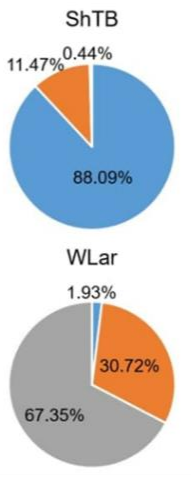

Fixed carbons

Figure 1. Comparison of physical parameters of biochars produced

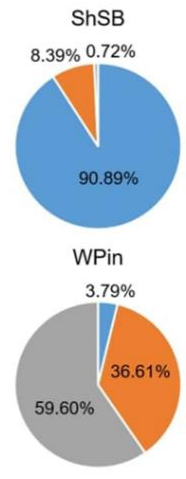

口 

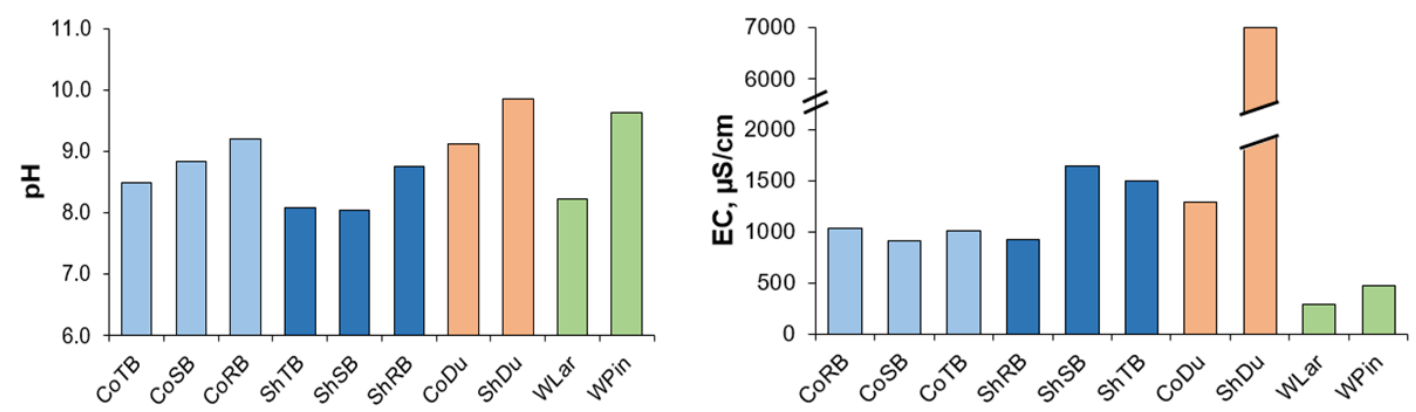

Figure 2. Physico-chemical parameters (pH, EC) of biochars

Redox potentials of biochar produced were varied from -56.33 to $-156.77 \mathrm{mV}$. The $\mathrm{pE}$ content was negative for all biochar samples and the highest value was noticed in sheep dung biochar (ShDu). Compared to other biochars, wood biochar had the lowest EC and TDS content, depending on the compounds in the raw material. The highest values of EC and TDS were found in biochar produced from sheep dung $7.04 \mathrm{mS} / \mathrm{cm}$ and $3510 \mathrm{ppm}$, respectively. In the study by [20], the EC value of cow bone biochar was 1.75 , and our results were close to that. Probably sheep manure was sampled with some soil underneath.

Cation exchange capacity (CEC) of biochars were ranged from 12.9 to $23.5 \mathrm{cmol} / \mathrm{kg}$. The highest value of CEC was detected in sheep dung biochar ( $\mathrm{ShDu}$ $23.5 \mathrm{cmol} / \mathrm{kg}$ ). Cow rib biochar (CoRB) was shown higher CEC result $(15.59 \mathrm{cmol} / \mathrm{kg})$ among cow bones biochars. Previously, in the study by [20], the CEC value of cow bone biochar was $16.79 \mathrm{cmol} / \mathrm{kg}$, and our results were a bit lesser. In addition, sheep spine biochar (ShSB) was shown higher CEC results (16.99 $\mathrm{cmol} / \mathrm{kg}$ ) among sheep bones biochars. In study by [21], the CEC value of pine biochar was 13.47 $\mathrm{cmol} / \mathrm{kg}$ and consistent with our result. The base cation saturation of the biochars produced from different biowastes is given in Figure 3.

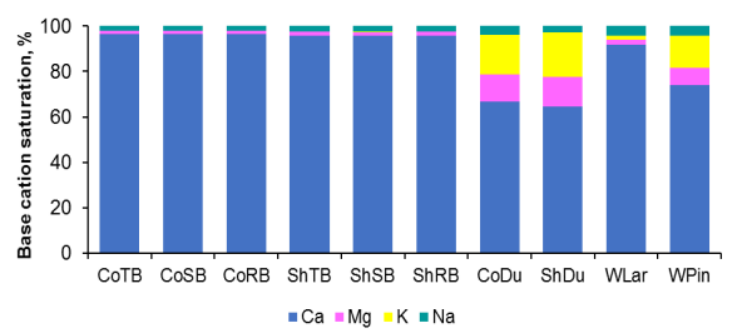

Figure 3. Base cation saturation of biochars

Base cations are expressed as the sum of calcium, magnesium, potassium, and sodium ions. Compared to cow-bones biochar, the sheep bones biochar had lower $\mathrm{Ca}$ content and higher $\mathrm{Mg}, \mathrm{K}$, and $\mathrm{Na}$ content.
Compared to animal-based biochars, while bone biochars showed (0.06-0.26\%) and dung biochars showed higher $\mathrm{K}$ content immediately more than 70 times. The large variability in CEC may be due to many factors that affected the surface properties of biochar, such as the effect of temperature and raw material.

\subsection{Biochar surface and pore characterization}

The macropores of the surface could only be seen from the biochar SEM images. Mesopores and micropores of the biochars were unlikely to be seen due to the instrument's lack of the capability. SEM analysis was performed to determine the pores of the biochars, as shown in Figure 4.

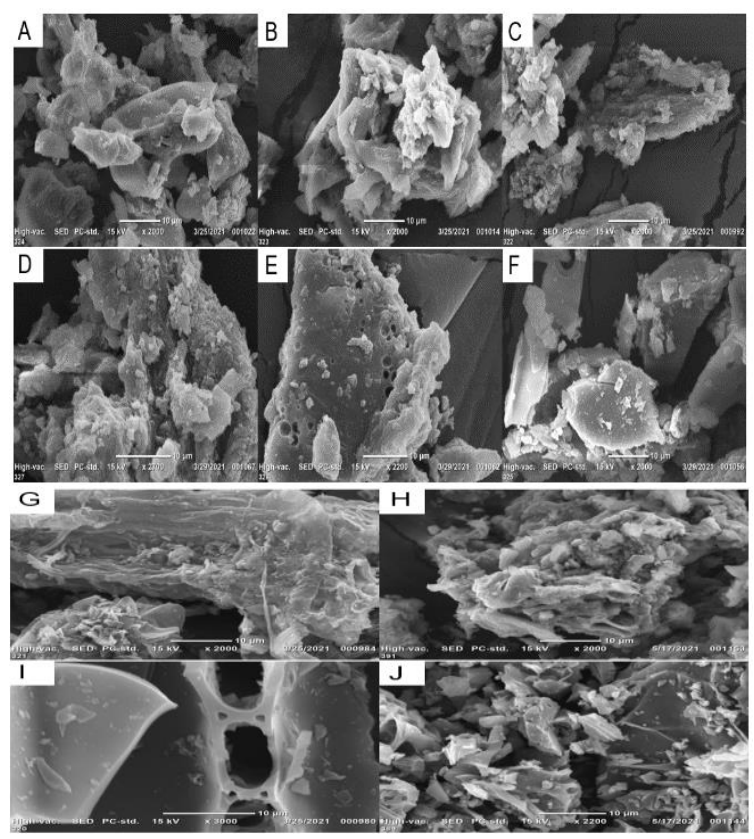

Figure 4. The SEM images of biochars samples: (A) CoTB, (B) CoSB, (C) CoRB, (D) ShTB, (E) ShSB, (F) ShRB, (G) CoDu, (H) ShDu, (L) WLar, (J) WPin 
Table 2. Results of methylene blue adsorption and specific areas $\left(\mathrm{S}_{\mathrm{MB}}\right), \mathrm{C}_{0}=50 \mathrm{mg} / \mathrm{L}$

\begin{tabular}{|c|c|c|c|c|c|c|c|c|c|c|}
\hline Biochar & CoTB & CoSB & CoRB & ShTB & ShSB & ShRB & CoDu & ShDu & WLar & WPin \\
\hline $\mathrm{C}_{\mathrm{e}}, \mathrm{mg} / \mathrm{L}$ & 4.96 & 11.32 & 5.54 & 18.61 & 8.16 & 23.60 & 11.47 & 4.50 & 28.17 & 49.10 \\
\hline $\mathrm{qe}, \mathrm{mg} / \mathrm{g}$ & 45.04 & 38.68 & 44.46 & 16.83 & 41.84 & 26.40 & 38.53 & 45.50 & 21.83 & 0.90 \\
\hline $\mathrm{K}_{\mathrm{L}}, \mathrm{L} / \mathrm{mg}$ & 0.03 & 0.02 & 0.05 & 0.01 & 0.03 & 0.01 & 0.08 & 0.05 & 0.01 & 0.00 \\
\hline$q_{\max }, \mathbf{m g} / \mathrm{g}$ & 229.64 & 109.94 & 177.69 & 153.38 & 216.87 & 269.47 & 65.83 & 181.61 & 47.76 & 5.96 \\
\hline $\mathbf{R}^{2}$ & 0.92 & 0.99 & 0.99 & 0.94 & 0.98 & 0.84 & 0.88 & 0.95 & 0.91 & 0.90 \\
\hline$S_{\text {MB }}\left(10^{-3} \mathrm{~km}^{2} / \mathrm{kg}\right)$ & 1.43 & 1.23 & 1.41 & 1.00 & 1.33 & 0.84 & 1.22 & 1.44 & 0.69 & 0.03 \\
\hline$\% \mathrm{RE}$ & 90.08 & 77.36 & 88.92 & 62.78 & 83.68 & 52.80 & 77.06 & 91.00 & 43.66 & 1.80 \\
\hline
\end{tabular}

Table 3. Estimation of micropores of the surface area using iodine adsorption number of biochars

\begin{tabular}{|l|l|l|l|l|l|l|l|l|l|l|}
\hline \multirow{2}{*}{$\mathbf{m}, \mathbf{g}$} & \multicolumn{2}{|l}{ Iodine adsorption number (IAN), mg/L } \\
\cline { 2 - 13 } & CoTB & CoSB & CoRB & ShTB & ShSB & ShRB & CoDu & ShDu & WLar & WPin \\
\hline 0.01 & 2931 & 3274 & 5734 & 1257 & 3419 & 2562 & 388 & 349 & 1397 & 2433 \\
\hline 0.10 & 349 & 460 & 2246 & 301 & 451 & 471 & 165 & 153 & 157 & 410 \\
\hline 1.00 & 186 & 242 & 311 & 107 & 172 & 246 & 147 & 45 & 108 & 206 \\
\hline
\end{tabular}

Table 4. TN and TC content of biochars

\begin{tabular}{|l|l|l|l|l|l|l|l|l|l|l|}
\hline Biochar & CoTB & CoSB & CoRB & ShTB & ShSB & ShRB & CoDu & ShDu & WLar & WPin \\
\hline TN, \% & 8.03 & 12.55 & 11.82 & 6.59 & 10.33 & 8.33 & 17.67 & 10.42 & 22.67 & 18.43 \\
\hline TC, \% & 9.16 & 14.42 & 12.06 & 8.04 & 11.88 & 9.29 & 36.25 & 30.04 & 80.27 & 89.43 \\
\hline
\end{tabular}

The standard deviation of the equipment was TN $( \pm 0.2)$ and $\mathrm{TC}( \pm 1.0)$.

As shown in Figure 4, the macropores are visible in the image (E). Although not visible to the naked eye, the capacity of mesopores and micropores was further determined by the methylene blue adsorption and iodine adsorption number methods.

\subsection{Methylene Blue Adsorption (MB)}

Adsorption of the methylene blue onto sorbent was described by using Langmuir isotherm and mesopores structural parameters $\left(\mathrm{S}_{\mathrm{MB}}\right)$ was determined of biochars are shown in Table 2.

Cow thigh bone biochar (CoTB) showed that could remove over $90.08 \%$ methylene blue in an aqueous solution, as shown in Table 2. The surface area of the biochars was ranged from 0.03 to 1.44 $\left(10-3 \mathrm{~km}^{2} / \mathrm{kg}\right)$. The $\mathrm{S}_{\mathrm{MB}}$ value of pine firewood biochar (WPin) was 0.03 and that of larch firewood biochar (WLar) was 0.69, which had more excellent mesoporous properties by WPin. Sheep dung biochar (ShDu) had the most surface area from dung biochars, while cow thigh bone biochar had the most surface area from animal bone biochars.

\subsection{Iodine Adsorption Number (IAN)}

Micropores of biochar were determined by iodine adsorption number. In this study, we were chosen three types of mass content biochars and the iodine adsorption number results are shown in Table 3.

The IAN of 10 biochars were determined by the adsorption of iodine in 3 different mass content from an aqueous solution. Biochars with high iodine numbers had excellent in removing small-sized contaminants [17]. CoRB showed the highest absorption number shown twice as much as ShRB. Firewood biochar provided more adsorption than manure biochar and WPin adsorbed slightly more than WLar. Although the number of iodine adsorption in dung biochar was the lowest, the adsorption of methylene blue number was higher than that of firewood, indicating a more mesoporous structure than micropores.

\subsection{Biochar Elemental Composition}

The CNO- analysis is a form of elemental analysis that measures only the carbon and nitrogen content of a sample. The results for TN and TC of biochar are shown in Table 4.

In terms of total carbon (TC) and total nitrogen (TN), the bone biochars had the lowest content, while the dung biochars had the middle content, and the firewood biochars have the highest content, and TC of firewood biochars was almost 8 times higher than 
the others. This proves that wood biochar was almost entirely an organic compound. The results of the [19] study showed that the TC content of cow manure $(36.18 \%)$ was consistent with our results. The highest TC content of pinewood biochar (WPin) was $89.43 \%$.
The bone biochars were low in organic matters, as shown in Figure 1, and the high ash content indicates the high levels of inorganic matters.

Table 5. Trace elements in the produced biochars

\begin{tabular}{|c|c|c|c|c|c|c|c|c|c|c|c|}
\hline \multicolumn{2}{|c|}{ Biochar } & CoTB & CoSB & CoRB & ShTB & ShSB & ShRB & CoDu & ShDu & WLar & WPin \\
\hline \multirow{8}{*}{ 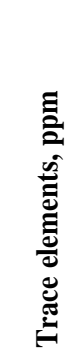 } & As & 0.006 & 0.006 & 0.008 & 0.006 & 0.005 & 0.006 & 0.011 & 0.014 & 0.005 & 0.004 \\
\hline & Cd & 0.005 & 0.005 & 0.005 & 0.005 & 0.005 & 0.005 & 0.006 & 0.006 & 0.005 & 0.005 \\
\hline & Co & 0.011 & 0.011 & 0.010 & 0.011 & 0.011 & 0.010 & 0.021 & 0.021 & 0.007 & 0.008 \\
\hline & $\mathrm{Cr}$ & 0.108 & 0.074 & 0.072 & 0.107 & 0.073 & 0.074 & 0.076 & 0.068 & 0.038 & 0.051 \\
\hline & $\mathbf{N i}$ & 0.139 & 0.129 & 0.115 & 0.133 & 0.145 & 0.123 & 0.093 & 0.084 & 0.036 & 0.047 \\
\hline & Zn & 0.495 & 0.627 & 0.497 & 0.556 & 0.573 & 0.454 & 0.546 & 0.558 & 0.103 & 0.330 \\
\hline & $\mathbf{C u}$ & 0.046 & 0.027 & $<0.010$ & 0.074 & 0.045 & 0.038 & 0.035 & 0.100 & $<0.010$ & $<0.010$ \\
\hline & $\mathbf{S r}$ & 1.556 & 1.495 & 1.278 & 1.606 & 1.440 & 1.680 & 0.813 & 0.535 & 0.154 & 0.186 \\
\hline
\end{tabular}

$-\mathrm{Pb}$, Mo below detection limit.

The results are shown in Table 5, which describes the trace elements in biochar. The arsenic (As) and cobalt (Co) content of dung biochar were twice that of other biochar. The chromium $(\mathrm{Cr})$ content of cow and sheep thigh bone biochars were ranged from 31.5 to $61.5 \%$ and higher than other biochars. Compared to other biochars, wood biochar had the highest nickel (Ni) and zinc ( $\mathrm{Zn})$ content, while copper (Co), lead $(\mathrm{Pb})$, and molybdenum $(\mathrm{Mo})$ content did not reach the detection limit. Nickel and zinc are transition metals. So they may have migrated to wood that has been around for a long time. The strontium (Sr) content of animal-derived biochars was almost 10 times higher than plant-derived biochars.

\subsection{Biochar Chemical Composition with Spectra Parameters}

Biochar FTIR results are shown in Figure 5. The bone biochars FTIR spectra show that the frequency range $1010 \mathrm{~cm}^{-1}, 605 \mathrm{~cm}^{-1}$, and $590 \mathrm{~cm}^{-1}$ reveal the peaks corresponding to $-\mathrm{PO}_{4}$ bonds (Figure $5 \mathrm{~A}$ ). The small peak size is due to the loss of water at high temperatures during pyrolysis. The peaks observed 1410 and $880 \mathrm{~cm}^{-1}$ are attributed to the $-\mathrm{CO}_{3}$ bond. In general, these spectra showed the adsorption bands that correspond to the structural composition of the bone biochar [22].

Sheep dung (ShDu) FTIR spectrum shows that the peaks corresponding to the $-\mathrm{OH}$ bond occur in the frequency range of $3600 \mathrm{~cm}^{-1}$ to $3000 \mathrm{~cm}^{-1}$ (Figure $5 \mathrm{~B})$. The dung biochars show a strong peak observed at $1000 \mathrm{~cm}^{-1}$ is associated with the $\mathrm{Si}-\mathrm{O} / \mathrm{C}-\mathrm{O} / \mathrm{C}-\mathrm{N}$ bond. The low peak observed at $3600 \mathrm{~cm}^{-1}$ is associated with $-\mathrm{N}-\mathrm{H}$. These results coincided with the peak of [23, 9] and [24] study the dung biochar differed from other biochars in that it contained the $(-\mathrm{N}-\mathrm{H})$ group.
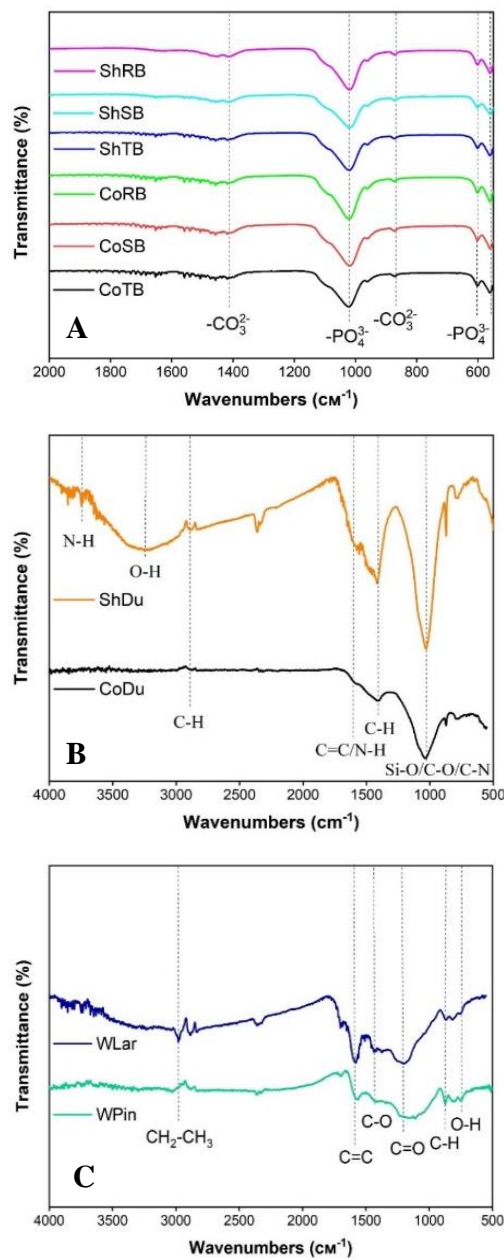

Figure 5. The FTIR spectra of the biochars: (A) bone biochars, (B) dung and (C) firewood biochars. 
Specific peaks observed in WLar and WPin (Figure 5C) observed at $750 \mathrm{~cm}^{-1}, 810 \mathrm{~cm}^{-1}$ and $\sim 1400 \mathrm{~cm}^{-1}$ corresponded to $\mathrm{O}-\mathrm{H}, \mathrm{C}-\mathrm{N}$, and $\mathrm{C}-\mathrm{O}$ vibrations. In addition, peaks of 1250 and $1600 \mathrm{~cm}^{-1}$ due to stretching vibrations of aromatics $\mathrm{C}=\mathrm{O}$ and $\mathrm{C}=\mathrm{C}$ bonds. The peak observed at $3000 \mathrm{~cm}^{-1}$ is associated with $-\mathrm{CH}_{2}-\mathrm{CH}_{3}$.

The purpose of the XRD diffraction pattern is to study the crystals of the material. Figure $6 \mathrm{~A}$ shows that the diffraction pattern of bone biochars is overlapped by ten peaks of $26^{\circ}$ to $53^{\circ}$. These are hydroxyapatite and calcium hydrogen phosphate hydroxide. The results of other researchers [25] also show that (HA) is the most common.
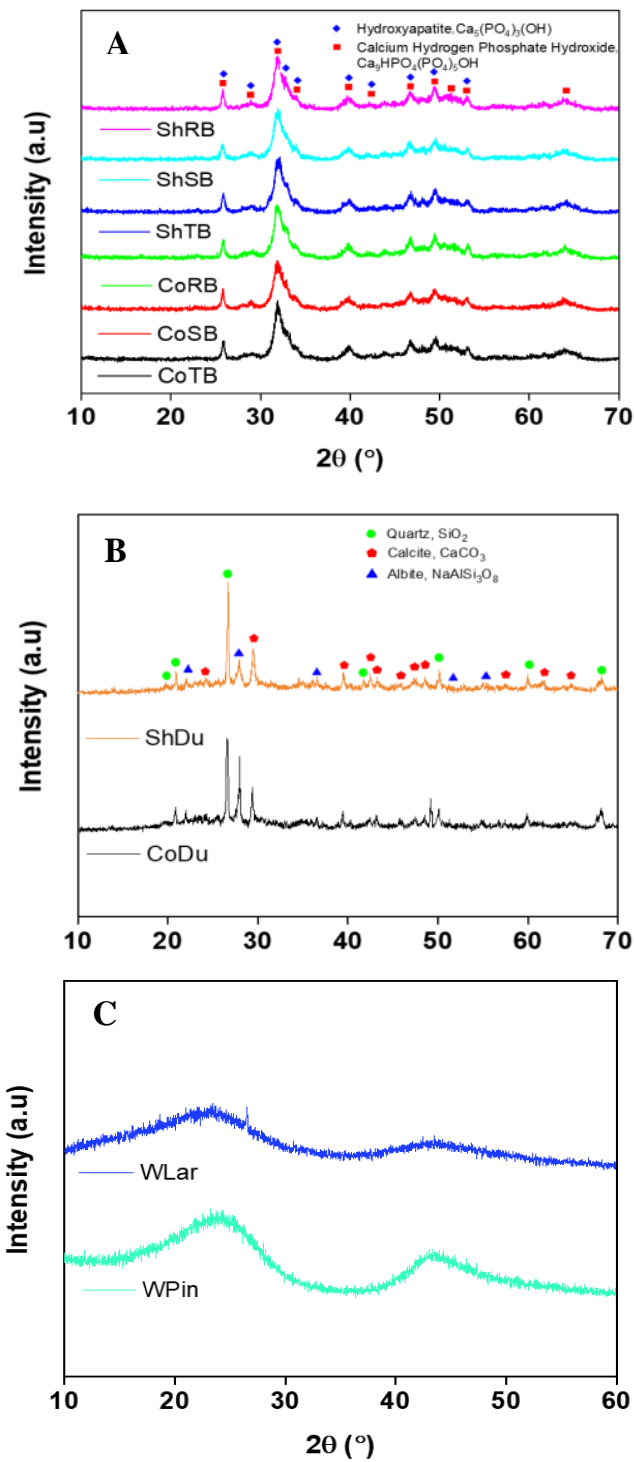

Figure 6. The XRD spectra of the biochars: (A) bone biochars, (B) dung, and (C) firewood biochars
Hydroxyapatite (HA) is a naturally occurring mineral form of calcium apatite that shows good biocompatibility and is an excellent candidate for bone repair and substitution [26]. Dung biochar XRD analysis revealed crystalline compounds such as quartz, calcite, and albite. The presence of calcite and quartz in the biofuels extracted from pig manure [27] also confirms the results of our study. The absence of crystalline peaks in the firewood (Figure 6C) XRD model confirms that it contains primarily amorphous compounds as a result of cellulose decomposition. It shows the structure of randomly oriented aromatic carbons. The study of pine biochar also showed that the XRD analysis was amorphous [28].

\section{CONCLUSION}

Biochars produced from usual animal-based biowastes (bones and dungs) in Mongolia have shown superior physic-chemical and structural characteristics over plant-based biowastes (larch wood and pine wood). Especially, cow bone biochars own great values of adsorbent characteristics, thus these biochars can be used for cleaning-up of various contaminants in water and soil. The application of biowaste-derived biochars can simultaneously reduce biowaste size in the environment and reuse it as an environmentally friendly valuable product.

\section{REFERENCES}

[1] Guanamantha I.M., Widana G.A.B., (2018) Characterization the potential of biochar from cow and pig manure for geoecology application. IOP Confenrence Series: Earth Environmental Science, Vol. 131, 1-2.

[2] Tomczyk A., Sokołowska Z., Boguta P., (2020) Biochar physicochemical properties: pyrolysis temperature and feedstock kind effects. Environmental Science and Biotechnology, Vol. 19, 191-215.

[3] Lehmann J., Joseph S., (2009) Biochar environmental management science and technology. Earthscan publisher, 3.

[4] Ahmad M., Rajapaksha A.U., Lim J.E., Zhang M., Bolan N., et al., (2014) Biochar as a sorbent for contaminant management in soil and water: A review. Chemosphere, Vol. 99, 19-33.

[5] Crombie K., Masek O., Saranp S., Brownsort P., Cross A., (2013) The effect of pyrolysis conditions on biochar stability as determined by three methods. GCB Bioenergy, 122-131. 
[6] Elnour A.Y., Alghyamah A.A., Shaikh H.M., Poulose A.M., Al-Zahrani S.M., et al., (2019) Effect of Pyrolysis Temperature on Biochar Microstructural Evolution, Physicochemical Characteristics, and Its Influence on Biochar/Polypropylene Composites. Applied sciences, 2-4.

[7] Zhao S., Ta N., Wang X., (2017) Effect of Temperature on the Structural and Physicochemical Properties of Biochar with Apple Tree Branches as Feedstock Material. Energies, 2-4.

[8] Rafiq K.M., Robert T.B., Rafiq M.T., Shang Z., Joseph S., (2016) Influence of Pyrolysis Temperature on Physico-Chemical Properties of Corn Stover (Zea mays L.) Biochar and Feasibility for Carbon Capture and Energy Balance. PLOS ONE, Vol. 11(6), 3-4.

[9] Domingues R.R., Trugilho P.F., Silva C.A., Melo I.C.N., Melo L.C., Magriotis Z.M., Sanchez-Monedero M.A., (2017) Properties of biochar derived from wood and high-nutrient biomasses with the aim of agronomic and environmental benefits. PLOS ONE, Vol. 12, 34.

[10] Nartey O., Zhao B., (2014) Biochar Preparation, Characterization, and Adsorptive Capacity and Its Effect on Bioavaibility of Contaminants: An Overview. Hindawi Publishing Corporation, 12.

[11] Xiao J., Hu R., Chena G., (2019) Micro-nanoengineered nitrogenous bone biochar developed with a ball-milling technique for high-efficiency removal of aquatic $\mathrm{Cd}(\mathrm{II}), \mathrm{Cu}(\mathrm{II})$ and $\mathrm{Pb}(\mathrm{II})$. Journal of Hazardous Materials, 1-2.

[12] Munkhbat B., (2018) Biochar in agriculture and environmet, Ulaanbaatar: Soyombo Printing.

[13] Schmidt H.P., Bucheli T., Kammann C., Glaser B., Abiven S., Leifeld J., (2015) European Biochar Certificate-Guidelines for a Sustainable Production of Biochar.

[14] Rippy J.F., Nelson P.V., (2017) Cation Exchange Capacity and Base Saturation Variation among Alberta, Canada, Moss Peats. HortScience: a publication of the American Society for Horticultural Science, 349-352.

[15] Kharel G., Sacko O., Feng X., Morris J.R., Phillips C.L., (2019) Biochar Surface Oxygenation by Ozonization for Super High Cation Exchange Capacity.
[16] Nunes C., Guerreiro M., (2011) Estimation of surface area and pore volume of activated carbons by methylene blue and iodine numbers. Quimica Nova, Vol. 34, 472-476.

[17] Itodo A., Abdulrahman F., Hassan L., Maigandi S., Itodo H., (2010) Application of Methylene Blue and Iodine Adsorption in the Measurement of Specific Surface Area by four Acid and Salt Treated Activated Carbons. New York Science Journal, 25-33.

[18] Long J., Song H., Jun X., Sheng S., Lun-shi S., Kai X., Yao Y., (2012) Release characteristics of alkali and alkaline earth metallic species during. Bioresource Technology, 278-284.

[19] Stylianou M., Christou A., Dalias P., Polycarpou P., Michael C., et al., (2020) Physicochemical and structural characterization of biochar derived from the pyrolysis. Journal of the energy institute, 1-42.

[20] Sukartono., Utomo W.H., Nugroho W.H., Kusuma Z., (2011) Simple biochar production generated from cattle dung and coconut shell. Journal of Basic and Applied Scientific Research, 1680-1685.

[21] Huff M.D., Kumar S., Lee J.W., (2014) Comparative analysis of pinewood, peanut shell, and bamboo biomass derived biochars produced via hydrothermal conversion and pyrolysis. Journal of Environmental Management, 303308.

[22] Rojas-Mayorga C.K., (2015) Physico-chemical characterization of Metal-doped bone chars and their adsorption behavior for water defluoridation. Applied Surface Science, 748760.

[23] Joseph S., Pow D., Dawson K., Mitchell D.R. G., Rawal A., (2015) Feeding Biochar to Cows: An Innovative Solution for Improving. Pedosphere, 666-679.

[24] Kiran Y.K., Barkat A., Cui X.Q., Feng Y., Pan F.S., et al., (2017) Cow manure and cow manure-derived biochar application as a soil amendment for reducing cadmium availability and accumulation by Brassica chinensis L. in acidic red soil. Journal of Integrative Agriculture, Vol. 16, 724-724.

[25] Nisar J., Razaq R., Farooq M., Iqbal M., Khan R. A., Sayed M., (2017) Enhanced biodiesel production from Jatropha oil using calcined 
waste animal bones as catalyst. Renewable Energy, 111-119.

[26] Zhu X., Radovic-Moreno A. F., Wua J., Langer R., Shi J., (2014) Nanomedicine in the management of microbial infection - Overview and perspectives. Nanotoday, Vol. 9, 478-498.

[27] Cao X., Harris W., (2010) Properties of dairymanure-derived biochar pertinent to its potential use in remediation. Bioresource Technology, 5222-5228.

[28] Lonappan L., Rouissi T., Brar S.K., Verma M., Surampalli R.Y., (2018) Adsorption of diclofenac onto different biochar. Data in Brief, 460-465. 